\title{
The significance and interpretation of congenital hypertrophy of the retinal pigment epithelium (CHRPE) diagnosed in patients with Familial Adenomatous Polyposis: A review
}

\author{
Paula Cristina Steffen Novelli ${ }^{1}$, Anelise Stachewski Russo ${ }^{2}$, Carlos Augusto Real Martinez ${ }^{3}$ and Fábio Guilherme Campos ${ }^{4 *}$ \\ ${ }^{1}$ São Francisco University, Bragança Paulista, Brazil \\ ${ }^{2}$ Portuguese Hospital Benefit in Sao Paulo, Sao Paulo, Brazil \\ ${ }^{3}$ Campinas State University, Campinas, São Paulo and São Francisco University Medical School, Bragança Paulista, Brazil \\ ${ }^{4}$ University of São Paulo Medical School, São Paulo, Brazil
}

\begin{abstract}
Classical Familial Adenomatous Polyposis (PAF) is a genetic disease with autossomal inheritance related to germline mutations in the $A P C$ or $M U T Y H$ genes. Mutation carriers usually develop polyps throughout the gastrointestinal tract at the beginning of adolescence, mainly in the colon. Some of these patients may be diagnosed with some benign and malignant extraintestinal manifestations (MEI), one of them is the congenital hypertrophy of the retinal pigment epithelium (CHRPE). The present article aims to review and discuss the role of CHPE as a diagnostic marker in FAP patients. Although retinal lesions may be present since birth, family members at risk for developing FAP are usually advised to undergo screening during the second decade of life, when colonic adenomas develop. Thus, fundoscopy should be included as part of the clinical evaluation of FAP patients, especially in pediatric patients, as it is an inexpensive, non-invasive, easily accessible and enforceable exam. CHRPE is now considered a reliable clinical marker for FAP diagnosis and may in induce genetic analysis.
\end{abstract}

\section{Introduction}

Classical Familial adenomatous Polyposis (PAF) is a genetic disease with autosomal dominant inheritance related to germline mutations in the $A P C$ gene. Others belong to families exhibiting a recessive pattern of inheritance determined by mutations if MUTYH gene. PAF carriers may develop polyps throughout the gastrointestinal tract from the onset of adolescence, mainly in the colon. Those patients should undergo prophylactic colectomy to avoid development of colorectal cancer.

After the diagnosis of the "index" case, descendants should undergo clinical, endoscopic and genetic evaluation as they have a $25-50 \%$ risk of inheriting the disease. Genetic testing is now considered the more accurate tool to identify affected relatives, besides its associated cost in some countries.

Eventually, both benign and malignant extraintestinal manifestations (MEI) may be associated with this genetic disorder. Some of them are represented by cutaneous epidermoid cysts, osteomas, dental malformations, desmoid tumors, gastroduodenal adenomas, central nervous system, hepatobiliary and thyroid neoplasms $[1,2]$. On interesting feature is the occurrence of congenital hypertrophy of the retinal pigment epithelium (CHRPE).

The present article aims to review and discuss the role of CHPE as a diagnostic marker in FAP patients.

\section{History and incidence}

CHRPE was first described by Blair and Trempe in $1980[3,4]$. Since them, it has been considered a strong PAF marker and a common
MEI, with reported incidence varying from 58 to $92 \%$. However, this ophthalmological alteration may also be found in 1.2 to $4.4 \%$ of population.

\section{Definition}

Congenital hypertrophy of the retinal pigment epithelium (CHRPE) is a rare benign lesion of the retina, usually asymptomatic and detected at routine eye examination. It results from a proliferation of pigmented epithelial cells, well defined, flat, does not cause visual symptoms if they do not reach the macula.

These retinal changes are represented by four or more lesions (sometimes multiple), rounded, flat, bilateral hyperpigmented (Figure 1) and divided into 5 presentation groups, by the Traboulsi classification. In different studies, the presence of at least four lesions, regardless of their size, corresponds to a sensitivity close to 0.630 with maximum specificity [5].

Diagnosis is established by funduscopy, and may be supplemented with fluorescent angiography and color retinography, which also

*Correspondence to: Fábio Guilherme Campos, Rua Padre João Manuel 222 Cj 120 - São Paulo, Brazil, CEP: 01411-000, E-mail: fgmcampos@terra.com.br

Key words: familial adenomatous polyposis (FAP); congenital hypertrophy of the retinal pigment epithelium (CHRPE); APC gene

Received: November 30, 2018; Accepted: December 10, 2018; Published: December 12, 2018 
Novelli PCS (2018) The significance and interpretation of congenital hypertrophy of the retinal pigment epithelium (CHRPE) diagnosed in patients with Familial Adenomatous Polyposis: A review

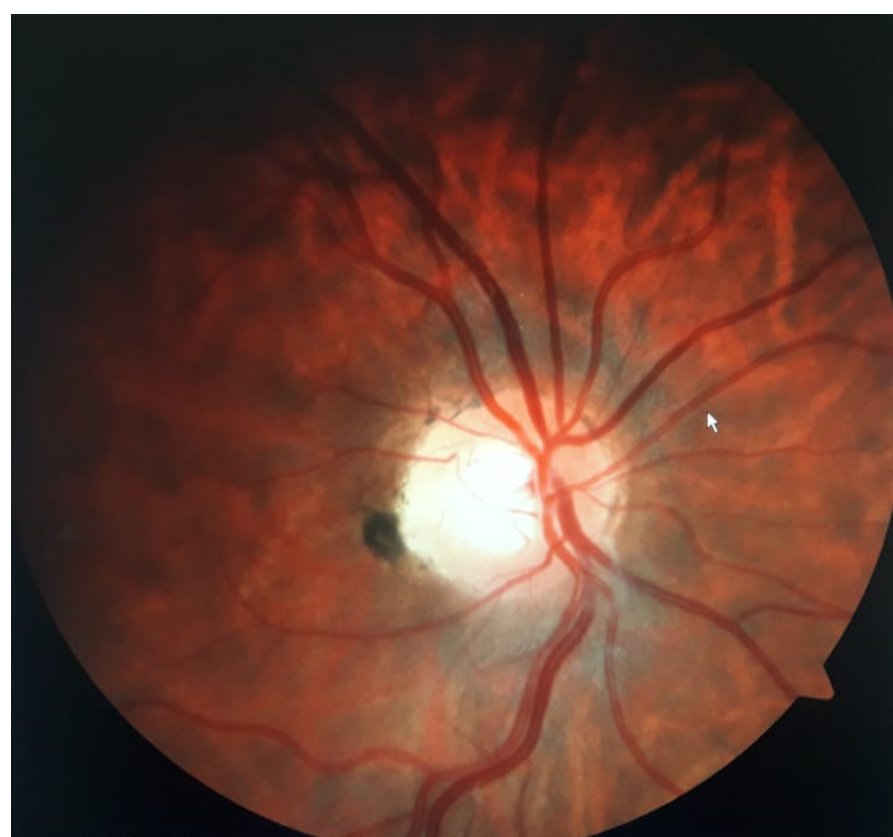

Figure 1. Retinography of patients with PAF and CHRPE. (Courtesy of the Unicamp Coloproctology Group)

contribute to the differentiation of other inflammatory, infectious and congenital chorioretinal lesions. The survey should include the most peripheral regions of the retina and all negative exams should be repeated a second time [6-8].

\section{Clinical relevance}

Family members at risk for developing FAP should be screened during the second decade of life, when colonic adenomas develop. However, it is recognized that retinal lesions may be present since birth. Thus, fundoscopy should be part of the clinical evaluation of FAP patients, especially in pediatric ones, as it is an inexpensive, noninvasive, easily accessible and enforceable exam $[8,9]$.

Ruhswurm et al. [10] demonstrated that ophthalmologic exams facilitate the predictive diagnosis in FAP patients and first-degree relatives. Once diagnosed, CHRPE becomes a reliable clinical marker for the diagnosis and may facilitate genetic analysis, by directing the localization of the mutation in the gene. So, it is considered an early marker of the pre-symptomatic phase of the disease.

In families not presenting CHRPE, however, the negative ophthalmological examination has no diagnostic value. Genetic marker studies should therefore be reserved for negative CHRPE family members and for the remaining individuals who, although belonging to positive CHRPE families, have negative ophthalmologic examinations [3,4,10-17].

On the other hand, Chagas et al. [11] reported that CHRPE may not allow diagnosis as early as linkage analysis, since its expression also increases with age, becoming maximal during the second decade of life (when colonic polyposis also develops).

Recognition of the CHRPE phenotype allows the search of a specific mutation in a smaller coding region of the APC gene, generally located in exons 9-15 and between codons 463 and 1387 of the $A P C$ gene.

CHRPE positive individuals present a $100 \%$ chance of having the genetic mutation [2]. Intra-familial variation of CHRPE gene expression is possible, indicating that negative fundoscopy individuals belonging to CHRPE positive families should not be excluded from the colonoscopic screening and or genetic analysis.

\section{Conclusion}

Screening for CHRPE is an easy method of diagnosing patients with FAP. In conjunction with other screening methods, it allows an early diagnosis mainly in pediatric patients. Simultaneously, it also allows an easier genetic analysis, focusing on the mutation in a smaller region of the APC gene. CHRPE lesions are now considered a noninvasive phenotypic marker that may allow early diagnosis during family screening.

\section{References}

1. Fields FGM, Dumarco RB (2012) Familial Adenomatous Polyposis (FAP): Extracolonic manifestations and causes of mortality. In: Treatise on Coloproctology. Atheneu 559563. ISBN: 978-85-3880301-0.

2. Fields FG, Habr-Gama A, Kiss DR, Actuí FC, Katayama F, et al. (2003) Extracolonic manifestations of familial adenomatous polyposis: incidence and impact on the evolution of the disease. Arq. Gastroenterol 40: 92-98.

3. Tiret A, Taiel-Sartral M, Tiret E, Laroche L (1997) Diagnostic value of fundus examination in familial adenomatous polyposis. Br J Ophthalmol 81: 755-758.

4. Nusliha A, Dalpatadu U, Amarasinghe B, Chandrasinghe PC, Deen KI (2014) Congenital hypertrophy of retinal pigment epithelium (CHRPE) in patients with familial adenomatous polyposis (FAP); the polyposis registry experience. $B M C$ Research Notes 7: 734

5. de Oliveira JC, Palmero EI, Rossi BM (2016) Genotype-Phenotype Correlation in Patients with Familial Adenomatous Polyposis. Thesis presented to the Postgraduate Program of the Pio XII Foundation - Barretos Cancer Hospital to obtain the Doctor's Degree in Oncology.

6. Dacarett F, Belt PH, Pineda H (2014) Congenital hypertrophy of retinal pigmen epithelium associated with familial adenomatous polyposis. Retina \& Vitreo.

7. Tiret A, Parc C (1999) Fundus lesions of adenomatous polyposis. Curr Opin Ophthalmol 10: 168-172. [Crossref]

8. Morale SA, Hernandez-Quintela E, Jimenez-Sierra JM, Villalobos JJ, Panduro A (1994) Congenital hypertrophy of the retinal pigment epithelium associated with familial adenomatous polyposis. Retina 14: 6-9. [Crossref]

9. Tiret A, Taiel-Sartral M, Tiret E, Laroche L (1997) Diagnostic value of fundus examination in familial adenomatous polyposis. $\mathrm{Br} J$ Ophthalmol 81: 755-758. [Crossref]

10. Ruhswurm I, Zehetmayer M, Dejaco C, Wolf B, Karner-Hanusch J (1998) Ophthalmic and genetic screening in pedigrees with familial adenomatous polyposis. $\mathrm{Am} \mathrm{J}$ Ophthalmol 125: 680-686.

11. Chagas C, Fidalgo P, Martins A, Barata A, Nobre Leitão C (1993) Value of Congenital Hypertrophy of Retinal Pigment Epithelium as Diagnostic Marker in Familia Adenomatous Polyposis. Gastroenterology and Surgery Services III. Portuguese Institute of Oncology. Ophthalmology Service. Hospital of Santa Maria, Lisbon. Acta Médica Portuguesa 6: 303-306.

12. Chen CS, Phillips KD, Grist S, Bennet G, Craig JE, et al. (2006) Congenital hypertrophy of the retinal pigment epithelium (CHRPE) in familial colorectal cancer. Fam Cancer 5: 397-404. [Crossref]

13. Nieuwenhuis MH, Vasen HF (2007) Correlations between mutation site in APC and phenotype of familial adenomatous polyposis (FAP): A review of the literature. Crit Rev Oncol Hematol 153-161. [Crossref]

14. Moore AT, Maher ER, Koch DJ, Charles SJ (1992) Incidence and significance of congenital hypertrophy of the retinal pigment epithelium (CHRPE) in familial adenomatous polyposis coli (FAPC). Ophthalmic Paediatr Genet 13: 67-71. [Crossref]

15. Mirinezhad SK, Mousavi F, Baghri M, Sepehri B, Ghavidel A, et al. (2018) Congenital Hypertrophy of Retinal Pigment Epithelium for Diagnosis of Familial Adenomatous Polyposis - the First FAP registry in Iran. Asian Pac J Cancer Prev 19: 167-169. [Crossref] 
Novelli PCS (2018) The significance and interpretation of congenital hypertrophy of the retinal pigment epithelium (CHRPE) diagnosed in patients with Familial Adenomatous Polyposis: A review

16. Aihara H, Kumar N, Thompson CC (2014) Diagnosis, surveillance, and treatment strategies for familial adenomatous polyposis: rationale and update. Eur J Gastroenterol Hepatol 26: 255-262. [Crossref]
17. Traboulsi EI, Maumenee IH, Krush AJ, Alcorn D, Giardiello FM, et al. (1990) Congenital Hypertrophy of the Retinal Pigment Epithelium Predicts Colorectal Polyposis in Gardner's Syndrome. Arch Ophthalmol 108: 525-526. [Crossref]

Copyright: (C2018 Novelli PCS. This is an open-access article distributed under the terms of the Creative Commons Attribution License, which permits unrestricted use, distribution, and reproduction in any medium, provided the original author and source are credited. 